Brazilian Journal
of Chemical
Engineering

ISSN 0104-6632

Printed in Brazil

www.abeq.org.br/bjche

Vol. 29, No. 02, pp. 371 - 384, April - June, 2012

\title{
REFINERY PRODUCTION PLANNING AND SCHEDULING: THE REFINING CORE BUSINESS
}

\author{
M. Joly \\ Centre of Excellence for Applied Industrial Automation Technology, CETAI, PETROBRAS, \\ Petroleo Brasileiro S/A, Rua do Lago 250, 05508-900, São Paulo - SP, Brazil. \\ Current Address: PETROBRAS RECAP Refinery, Phone: + (55) (11) 3795 9397, Fax: + (55) (11) 3597-9197, \\ Av. Alberto Soares Sampaio 2122A, 09380-904, Mauá - SP, Brazil. \\ E-mail: joly@petrobras.com.br
}

(Submitted: August 2, 2011 ; Revised: December 28, 2011 ; Accepted: February 9, 2012)

\begin{abstract}
Intelligent production planning and scheduling are of paramount importance to ensure refinery profitability, logistic reliability and safety at the local and corporate levels. In Brazil, such activities play a particularly critical role, since the Brazilian downstream model is moving towards a demand-driven model rather than a supply-driven one. Moreover, new and specialized non-linear constraints are continuously being incorporated into these large-scale problems: increases in oil prices implying the need for processing poor quality crudes, increasing demand and new demand patterns for petroleum products, new stringent environmental regulations related to clean fuels and start-up of new production technologies embedded into more complex refining schemes. This paper aims at clarifying the central role of refinery planning and scheduling activities in the Petrobras refining business. Major past and present results are outlined and corporate long-term strategies to deal with present and future challenges are presented.

Keywords: Refinery planning; Refinery scheduling; Operations research.
\end{abstract}

\section{INTRODUCTION}

The Brazilian energy sector has experienced an astonishing change in the last fifty years and, in particular, the oil sector has expanded in an unprecedented way. In this sense, Petrobras must be prepared to cope with new multidisciplinary challenges to sustain its competitiveness, since it deals with one of the world's longest and most complex supply chains, beginning at a natural resource in the ground and continuing all the way through to the end-users.

In Brazil, the complexity of the aforementioned problem is particularly marked, since its downstream business model is now moving towards a stiff competition demand-driven model rather than the conventional monopoly supply-driven one. At the same time, several new multidisciplinary constraints arise: increases in oil prices implying the need for processing poor quality crudes, increasing demand and new demand patterns for petroleum products including petrochemicals, new Brazilian stringent environmental regulations related to clean fuels, launching of new production technologies (e.g., heavy ends upgrading, product quality improvement, efficient fuel usage, refinery emission control strategies, in-line blending units) embedded into more complex refining schemes and subject to increasing complexity of the logistic hardware that interconnects crude oil terminals, refineries, and distribution centers.

In addition, the growing acknowledgement that the performance of catalytic processes is governed by the molecular rather than bulk properties of the feedstock has driven in-house development of a new set of highly specialized process models and operational constraints that are molecularly explicit. Brazilian refineries, like other oil companies, should

*To whom correspondence should be addressed 
quickly move towards the molecular management of their refining processes in order to meet product specifications as well as environmental regulatory requirements.

This nervous scenario is still subject to possible disruptions caused by various factors at global level that no oil company can control. Therefore, to maintain the profit margins in this ever-changing environment, the Petrobras refining area needs to have smarter strategies for safe, flexible and adaptive operations. This means that the work processes, abilities and tools need to be well adapted to support distinct business scenarios and the transition from one activity to the other has to be as quick and smooth as possible (Moro, 2009).

Such challenges will cause a substantial increase in the size and complexity of the refinery decisionmaking process in the years to come. Reliable automation based on integrated off-line and on-line advanced optimization tools is the key to achieve the refinery's true potential. Whereas commercial decision-making technology has provided converged solutions for refinery planning and scheduling problems since the 1970's (Bonner and Moore, 1979), currently there is the possibility of going beyond what is commercially attempted and available. This aims at exploiting new frontiers: detailed and integrated large-scale optimizationbased tools with strategic, operational and financial metrics. Rethinking current solution approaches (Agrawal and Balasubramanian, 2006) and cultural paradigms (Zhang, 2006; Zhang and Valleur, 2010) are mandatory practices to manage the modern refining business. Thus, it seems natural to refer to the 2010's as the decade of Operations Research (OR) in the refining business environment.

In this sense, this paper aims at clarifying the central role of refinery planning and scheduling activities in the Petrobras refining business. In the light of advances in OR technology, major past and present strategies suited to deal with present and future challenges are discussed.

\section{ROLE OF OPTIMIZATION IN THE REFINING BUSINESS}

Optimization is a crucial science for highperformance refineries (Zhang, 2006). The goal of refinery optimization is to push operation towards the maximal profit until it reaches the limit at which any further profitability increase is dependent on changes in the existing hardware. As pointed out by Moro (2009), many investment plans for refinery capacity expansion were postponed as a result of the recent world economy slowdown and the optimization of the existing plants, which had lost priority in favor of the design of new ones, came again to prominence. In other words, optimization also means flexibility (Zhang, 2006).

For an existing refinery, especially when it has been in operation for a considerable period of time, more and more shortcomings emerge, largely due to market dynamics and technology evolution. For instance, an existing plant may not have enough capacity to meet current and future market demand; it may not satisfy new environmental regulations and/or product specifications; it may consume too much energy; it may not have sufficient reliability, etc. Investing capital to build new units can directly solve those problems. However, revamping (debottlenecking) an existing plant is typically a much more attractive option, since it can usually be modified more quickly with less capital investment and risks than installing a new one. To maintain its competitiveness, oil refineries are constantly searching for optimization opportunities to improve their operations. Traditionally, oil refineries typically perform the following types of periodic optimization studies:

i. Strategic plans for future years and expansion projects;

ii. Annual plans for budgeting, term crude contracts and programmed maintenance shutdown planning;

iii. Monthly rolling plans for crude selection and conducting refinery operations in line with foreseen demands;

iv. Short-term (typically weekly) plans for finding operating strategies regarding either precise or a good level of knowledge about crude availability, product delivery, operational and logistic constraints, as well as economic issues;

v. Profitability improvement plans for local or plant-level modifications, and revamp projects.

Although the potential benefits of production planning optimization in oil refineries have long been observed with applications of linear programming in crude blending and product pooling (Symonds, 1955), refinery planning is currently a key-business layer since it represents not only the foundation for decisions that have the biggest impact on refinery profitability (see Kelly and Mann, 2003), but also a vital feedback for continuous revaluation of corporate supply-chain operation and performance. Supporting this activity, OR techniques have provided the automation to allow refinery planner teams to efficiently solve the integrated 
production problem at the strategic and tactical levels.

Strategic (long-term) planning is concerned with aggregated decisions interfacing the corporate supply chain (see Neiro and Pinto, 2004). Tactical (mediumterm) planning focuses on local decisions such as the assignment of production targets to process units, inventory management policy and logistic operation guidelines (Pinto and Moro, 2000a; Maravelias and Sung, 2009). Finally, short-term planning or scheduling addresses the operational level problem to determine the assignment of tasks to process units and the sequencing of tasks in each unit is a major concern (see Lee et al., 1996; Joly and Pinto, 2003).

Didactically, the planning activity is dedicated to define targets that make more money, whereas the scheduling activity should execute the optimal plan as much as possible, avoiding money-losing operations. In short, refinery planning can be regarded as a flowsheet optimization problem with multiple periods during which the plant is assumed to operate in the steady-state. This corresponds to solving problems ii and iii.

Since the planning model is not an aggregated scheduling model, an expressive amount of additional effort must be invested to support the corresponding decision-making process at the operational level. Refinery scheduling problems deal with timing, sizing, allocation and sequencing decisions embedded in a realistic non-linear world where specialized process models, complex blend correlations or optimized injection of expensive fuel additives must be considered. In short, scheduling is the development of a detailed (executable) plan able to implement the operation strategy idealized in the planning process, running the refinery up against physical and logical constraints. Such a decisionmaking process concerns the allocation of limited resources to competing tasks over time with the goal of optimizing some performance criteria. Since they are oriented to short-term real-world objectives, this class of large-scale combinatorial optimization problems typically requires solution approaches based on advanced OR technologies.

Actually, customized (or specialist) optimization solutions offer the precious flexibility to model particular technical and/or business rules, as synergistic, competitive or prohibitive relationships among resources, which may not be represented in a straightforward way by using standard commercial scheduling solutions. Although refinery scheduling is a prolific field for intense application of mathematical programming and hybrid techniques (Magalhães, 2004; Magatão et al., 2011), such technologies remain largely unexplored in commercial packages, in which applied optimization is typically restricted to blending operations.

In addition to the mathematical complexity issues, scheduling spans across the enterprise supplychain and handles several types of distinct information, attempting to connect the "dream" - the production plan - to the "real-world" - the operation. This enables a collaborative effort, better visibility and additional adjustments for improving economics (Swensen and Acuff, 2011). Hence, if not efficiently integrated into other corporate systems, the scheduling tool typically can end up using static data that may not be current (Agrawal and Balasubramanian, 2006).

Solving the last two aforementioned issues mathematical complexity and system integration would make dynamic scheduling a reality with valuable time-savings for the refinery scheduling team, thereby banishing mechanical work and making more time available to think.

Overcoming the challenge of migrating from a reactive scheduling to a predictive one, one can increase safety and profitability. Typically, profitability gains due to better scheduling quality provided by computer-aided decision-making technology have been projected as ranging from US\$ 0.10 to US\$ 0.15 per crude oil barrel processed (Moro, 2003). Hence, given the current refining capacity of around 2,000,000 bbl/day, one can estimate the overall Petrobras refining potential opportunity as US\$ 102x106 per year. However such estimates may be very conservative, since benefits ranging from US\$ 1.00 to as much as US\$2.00/bbl have already been identified at the advanced process control level (Latur, 2009). Moreover, since refinery scheduling interfaces with the corporate supply chain, it would not be surprising if such benefit were indeed greater by an order of magnitude.

\section{ROLE OF OPERATIONS RESEARCH IN REFINERY OPTIMIZATION}

The most successful refineries are those that monitor their performance closely, adjust their operations correspondingly, identify their key weaknesses and correct them promptly, especially during crisis events (Zhang, 2006). Although these principles are easy to understand, achieving them is a very complex task. Refinery planning and scheduling belong to the most difficult class of mathematical optimization problems studied in OR, the NP-Hard one (see Garey and Johnson, 1979; Vavasis, 1991). 
Over the last half-century, OR evolved as an applied science of understanding the nature of decision-making problems faced by human society and how to solve such problems through analytical techniques. In a world in which the natural resources are becoming scarce, the intrinsic multidisciplinary nature of the OR makes it an essential tool for intelligent management of a large set of human activities. It is not a coincidence that many problems of a theoretical nature resemble many real-world industrial problems, since the former may represent valuable abstractions to deal with the latter. As an illustrative example, the same optimal control technology currently used to solve mixed-integer dynamic optimization problems related to chemical engineering process design and control can be replicated to perform the immunopharmacogenomic optimal control of important human retroviral diseases, like AIDS (Joly and Pinto, 2006).

In fact, the general-purpose facet of OR renders it a polyvalent, strategic, know-how that enables oil companies to develop automation dedicated to its specialized, critical needs. Such singular flexibility to promptly replicate results based on general solution frameworks has also conferred on OR technology a prominent role in oil industry optimization (not confined to refineries). The first and most fruitful industrial applications of linear programming have been to refinery production planning (Charnes et al., 1952). So intense were the results that analogous approaches were immediately applied by the oil industry to exploration and production and distribution as well (Garvin et al., 1957).

In fact, publication of these articles opened up a whole array of new opportunities for the use and development of mathematical modeling to address industrial problems in surprising ways. New developments in methodologies took the form of new concepts, embodied in developments such as game theory, queuing theory, search theory, statistical decision theory, and information theory (as well as linear programming), which were bursting on the scene almost simultaneously. Such developments were then collected, nurtured, and extended in the disciplines that we now know as OR. For a concise review, see Cooper (2002).

Regarding refining optimization, the state-of-theart is to use NLP or mixed integer linear programming (MILP) for production planning analysis. In fact, the availability of LP- and NLPbased commercial software for refinery production planning, such as GRTMPS (Haverly Systems),
TRIOS (UOP Limited), RPMS (Honeywell Hi-Spec Solutions) and PIMS (Aspentech) has systematized the development of production plans of the whole refinery, which can be interpreted as general trends. On the other hand, many petroleum companies have developed their own LP tools in-house. This is not only because of the speed and robustness of LP, but, more importantly, because a complete value structure in terms of marginal values can be easily obtained, which provides meaningful information on solution explanation and sensitivity analysis. Since hierarchical decision-making frameworks continue to be required to handle complex supply-chain problems, such marginal information represents a critical link between planning and scheduling business layers, since the optimization drive must be vertically (i.e., hierarchically) consistent. Moreover, in-house developments have addressed novel issues in refinery planning problems, like rigorous analysis of the optimal solution by using advanced optimization techniques such as solution ranging, parametric analysis and goal programming, which may provide an a-priori evaluation of the solution robustness and flexibility (Guerra et al., 2011) and postoptimality analysis (Al-Shammari and BaShammakh, 2011).

\section{ROLE OF IN-HOUSE TECHNOLOGY DEVELOPMENT AS A COMPETITIVE DIFFERENTIAL}

Refining play a central role in the Petrobras supply-chain since it converts raw-material into finished products, aiming at achieving high customer satisfaction. In other words, the Petrobras image depends largely on a reliable production planning and scheduling committed to and in compliance with customer needs.

The scheduling problems that have to be solved to achieve this objective cover a wide range of specialized activities (from procurement and production to distribution and sales), time scales (from months to a few hours), and information across the enterprise's supply-chain. Therefore, integration is the keyword for any successful decision-making solution regarding refinery planning and scheduling processes.

Clearly, system integration is the first and principal motivating factor for Petrobras to develop in-house decision-making technology. Keeping core business and technological know-how inside the company is the second factor, since it confers self- 
government to solution maintenance and evolution as well as independence of software market dynamics and volatility, another aspect that cannot be neglected, as Petrobras has indeed experienced in the past. In-house developments can take full advantage of translating the company's specialized business and process know-how into efficient decisionmaking tools.

At this point, clean fuel technology may be presented as an illustrative motivating example. The global concern about the emission of pollutants has led to the establishment of stringent specifications for petroleum-derived fuels and increasing product specification requirements according to molecular composition should be expected (Albahri, 2005; Aye and Zhang, 2005; Hu and Zhu, 2001; Hu et al., 2002; Zhang and $\mathrm{Wu}, 2009$; Wu and Zhang, 2010). However, further improvements in the diesel hydrotreating operation will be dependent on the precise understanding of what happens in the reactor at the molecular level. In this sense, new process engineering technologies have been continuously developed to reduce greenhouse gas producing sulfur species in fuels like alkyl-substituted dibenzothiophenes, especially 4,6-dimethyldibenzothiophene, which has been reported to be the most refractory sulfur compound in deep hydrodesulfurization processes. The everincreasing know-how on the molecular information of refinery streams, allied to accumulated expertise in terms of comprehensive models of the hydrotreating operation from a molecular standpoint imply opportunities for large-scale optimization technology oriented to a molecular management of the refining process.

Nowadays unacceptable for designing new hydrodesulfurization systems, global sulfur analysis may also hide information for optimizing several processes with important roles reserved for the near future. Hence, novel planning and scheduling frameworks are required and should be supported by specialized, proprietary and/or confidential, molecular know-how. Therefore, reliable integration with corporate systems and databases from which current molecular information could be extracted in a straightforward way may become essential for the refining supply-chain optimization.

The Petrobras refining supply-chain is currently based on a traditional top-down hierarchic approach (Figure 1). Multi-level problem decomposition is adopted to render its computation feasible in a reasonable time; nevertheless, it is (probably) suboptimal, since no simultaneous optimization is performed. Here, "Data warehouse" concatenates the entire structure and can be understood as a relational and historical database that manages data input and output among heterogeneous applications.

Such heterogeneity may be found at distinct levels (Moro, 2009). When applications are provided by different software suppliers, they are typically based on different process representations. Among the major disadvantages, poor integration as well as hard model maintenance and consistency assurance among business layers may be cited, since redundant efforts from the refinery staff will be required.

However, commercial refinery planning and scheduling solutions usually form part of an integrated supply-chain software suite of the vendor and its use may become particularly attractive if the whole integrated solution is acquired. Otherwise, much effort in system integration to the refinery's management information systems (MIS) and enterprise resource planning (ERP) systems may be required to make its use feasible from a practical point of view. On the other hand, even if a single commercial supplychain integrator is chosen, heterogeneity typically arises from the fact that the component tools embedded in the solution were developed by different specialized teams and rely on different paradigms. Not rarely, such commercial supplychain suites are composed of different tools that were acquired and then integrated into a single software suite by the supplier. Apart from the undesirable dependence on a single supplier, adjustments to particular needs may be expensive or even compromised in this case. The ease of model maintenance by the refinery staff and a flexible architecture based on the latest in IT developments are additional features that should be carefully evaluated before acquiring commercial technology.

Currently, the availability of commercial technology for refinery planning implies that only part of the whole problem may be considered solved, since refineries do not operate on averages. In contrast, the short-term production objectives must be translated into discrete operational decisions. Scheduling tools differ from the planning ones in the sense that they are weakly automated, handle a lot of information on a more detailed problem and have higher frequency of execution. Therefore, a userfriendly, integrated and automated system is required in order to provide fast and reliable responses. As properly pointed out by Agrawal and Balasubramanian (2006), if systems are not efficiently integrated, it is left to the schedulers to remedy the situation by using e-mail and phones. 


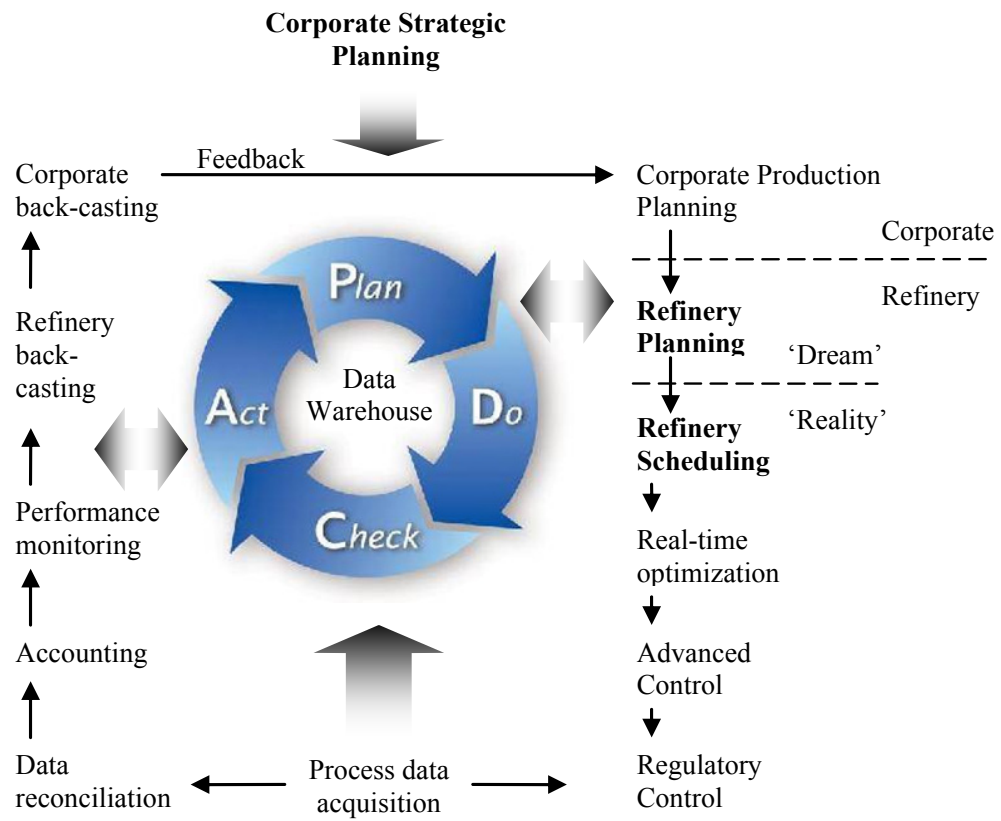

Figure 1: Schematic representation of a hierarchical decision-making framework

The current lack of efficient technology for scheduling automation remains the main obstacle to the integration of production objectives into process operations. A more efficient approach would incorporate current and future constraints in the synthesis of production schedules regarding non-linear model fidelity, predictive performance monitoring and expanded automated decision-making capabilities, as well as integration with corporate systems. Finally, the potential for efficiently connecting the production planning and scheduling layers (see Maravelias and Sung, 2009) is another key advantage of in-house development-based strategies for supply-chain optimization. Attempting to overcome such challenges, Petrobras is among the first oil companies that started in-house development oriented to produce corporate, integrated, refinery production decisionmaking technology. Since the mid 90's, the Petrobras IT sector has been continuously investing in the development and sophistication of BR-SIPP (Magalhães et al., 1998; Rodrigues and Joly, 2009), the Petrobras integrated refinery scheduling system (INPI proprietary grant 00067400). In its second version, the BR-SIPP technology is fully integrated into the Petrobras product inventory and quality database. Distillation assays (cut yields and qualities) as a function of unit temperature profiles are automatically calculated by another integrated corporate tool dedicated to crude management and blending optimization, namely Blend-BR. BR-SIPP is a multi-user event-based simulation tool dedicated to support short-term decisions ranging from crude and feedstock arriving in crude terminals up to finished oil product shipping by the refinery (Figure 2). Since it is a simulation-based tool, an initial scheduling solution must be provided. Automatic scheduling capabilities are currently being developed on the basis of metaheuristic approaches.

BR-SIPP is currently implemented in the Petrobras RECAP, RPBC, REGAP, REMAN, RLAM and REFAP S.A. refineries, which account for about $50 \%$ of the Petrobras refining capacity in Brazil. Since it is a general-purpose tool, BR-SIPP has also been introduced in the Petrobras biofuel refineries with a pilot implantation being carried out at the Candeias plant, in the state of Bahia. The relevance of this project should be seen in the light of a prodigious 10-fold expansion of Petrobras biofuel production in the last three years.

Besides being a vital decision-making tool for integrated crude oil scheduling, BR-SIPP has also been consolidated as an important information system as well. The scheduling information, previously restricted to a limited group or person, is now democratized within the refinery through a Citrix metaframe-based access, thereby enabling a collaborative effort, and better and faster responses. The new tool has replaced a set of non-standard and personal spreadsheets of difficult comprehension and maintenance. Production scheduling definitions, data and information are now being structured and standardized (Figure 3). As a consequence, the learning-curve of new engineers assigned to scheduling activity has been drastically reduced and the best work practices are easily replicated across the refineries. 


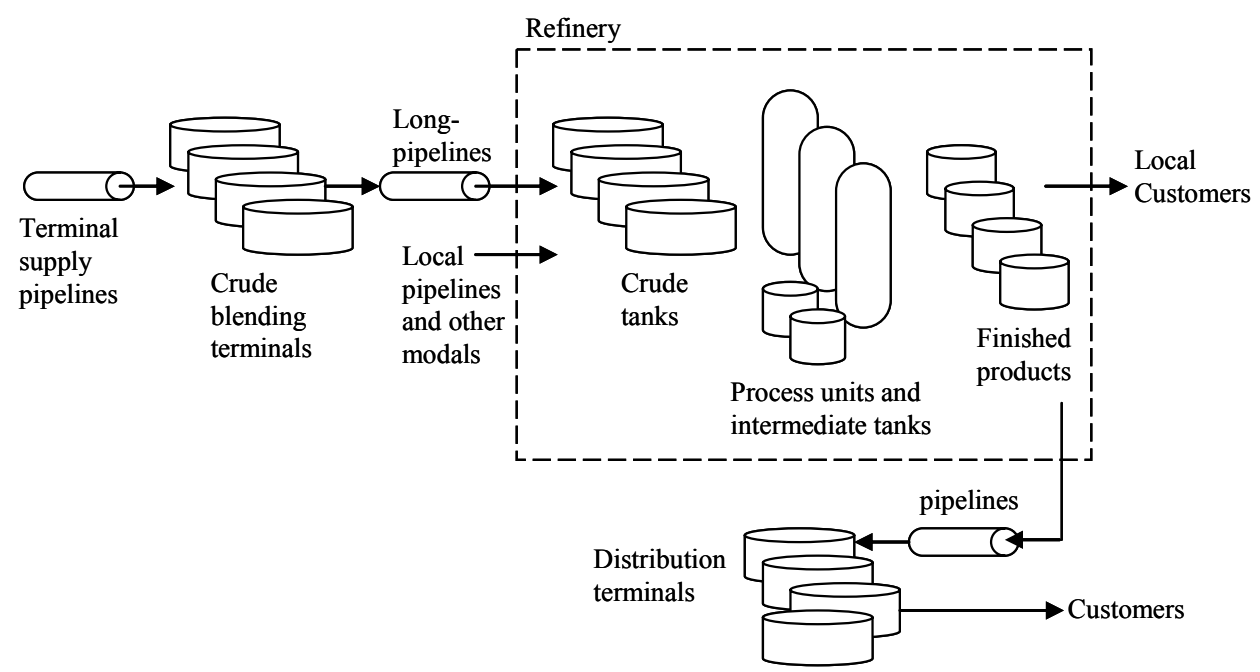

Figure 2: The problem scope addressed by BR-SIPP.

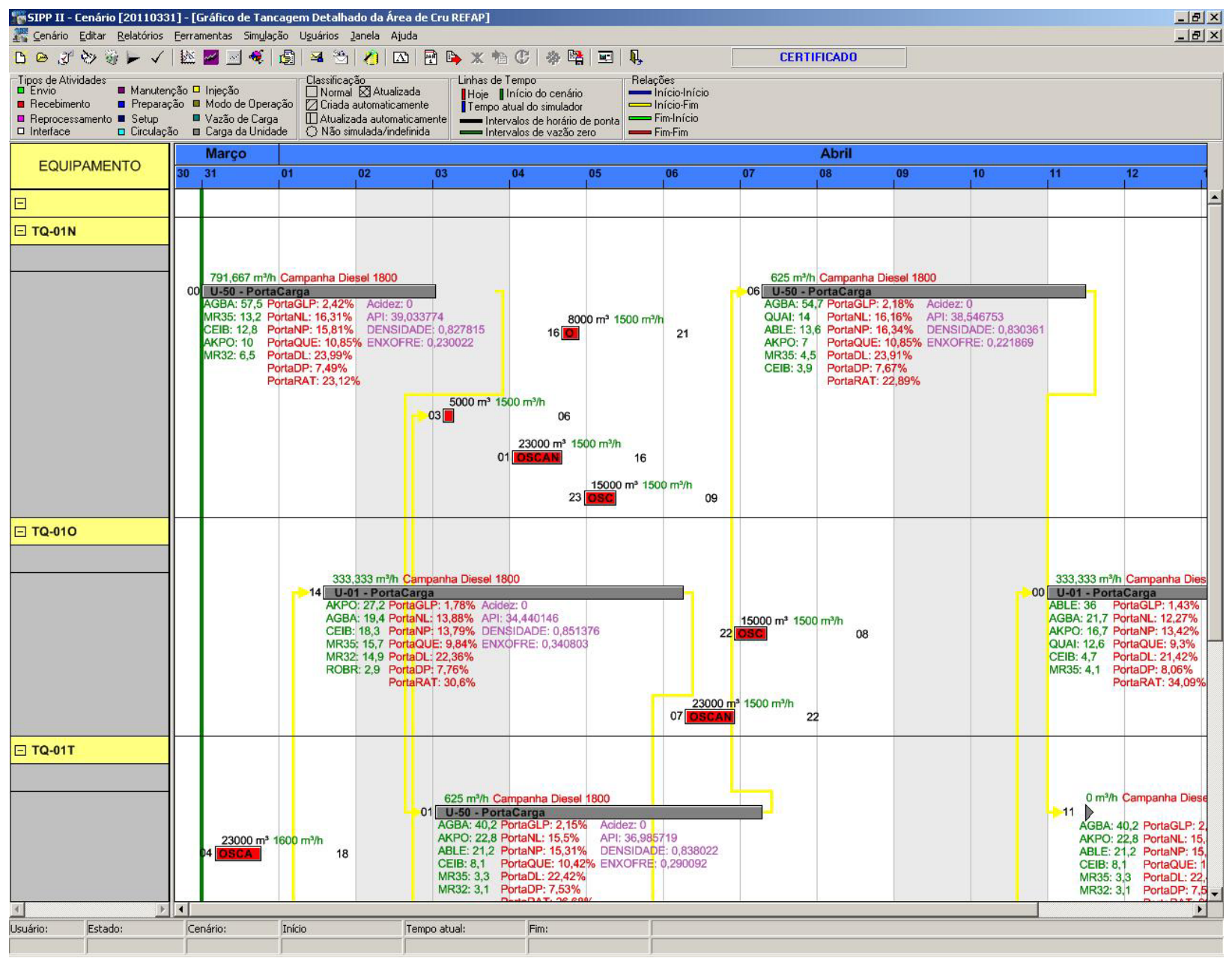

Figure 3: Gantt chart image from BR-SIPP. 
Despite clear qualitative advantages, evaluating quantitative benefits due to scheduling optimization remains a challenging task since the activity is embedded into a very dynamic environment and references will change according to current assumptions and constraints. Hence, obtaining an accurate measure of benefits produced by an optimized refinery scheduling may be a very expensive activity. Nevertheless, by periodically confronting the production planning objectives with the actual refinery performance one can obtain a quick numerical evaluation of the refinery's ability to achieve the optimal planned objective. In fact, Petrobras refineries that have concluded adoption of BR-SIPP technology have indeed been characterized by better performance (Figures 4 and 5). In Figure 4, relative gaps between monthly planned and achieved refinery production are depicted for the oldest three BR-SIPP implantations (RECAP, RPBC and REGAP) against a representative time horizon of the last 7 years. In this figure, average data are clustered by year and denote the relative difference module between the foreseen refinery planning defined at the beginning of a given month and the actual refinery production achieved at the end of the same month. Start-up times of BR-SIPP use at each refinery are illustrated by vertical lines. Data for refineries not yet supported by BR-SIPP are also presented, together with corresponding trend lines, from which one can note outstanding benefits for those refineries that have consolidated new work processes aided by decision-making scheduling technology. In addition, the impact of such benefits can vary among refineries according to the plant scope that is effectively covered with support of the scheduling tool. RECAP, the simplest and smallest among the evaluated refineries, has implemented a fully integrated refinery scheduling from the crude terminal to final product shipment and has produced better results than other more complex refineries (e.g.: RPBC and REGAP) in which the system operation has focused on the crude oil area and on some critical plant subsystems (see Figure 4).

Although such complex refining schemes may potentially have even more optimization opportunities to be exploited by an integrated production scheduling approach than simple ones, a more automated scheduling tool seems to be mandatory in these cases, since the operation of an event-based tool may become very expensive or even unfeasible in practical terms. Also contributing to better results, the integration of production planning and scheduling at RECAP has been enhanced with the expanded utilization of BR-SIPP over the entire plant scope, since it enables complementary planning feasibility analysis, daily planning model adherence verification and systematic refinery planning reruns regarding fixed variables related to short-term plant behavior forecasting from production scheduling data. As a result, the gap between theoretical production planning objectives and actual refinery performance has been particularly reduced in RECAP. Non-users of BR-SIPP have also experienced variable ranges of improvement by using (very) specialized local solutions and work processes typically supported by electronic spreadsheets, but the potential benefits associated with a multi-user integrated and standardized scheduling solution implementation, as a fast and reliable response to crisis or unexpected market opportunities, may be identified as a contributing factor for explaining the distinct slopes presented in Figure 4.

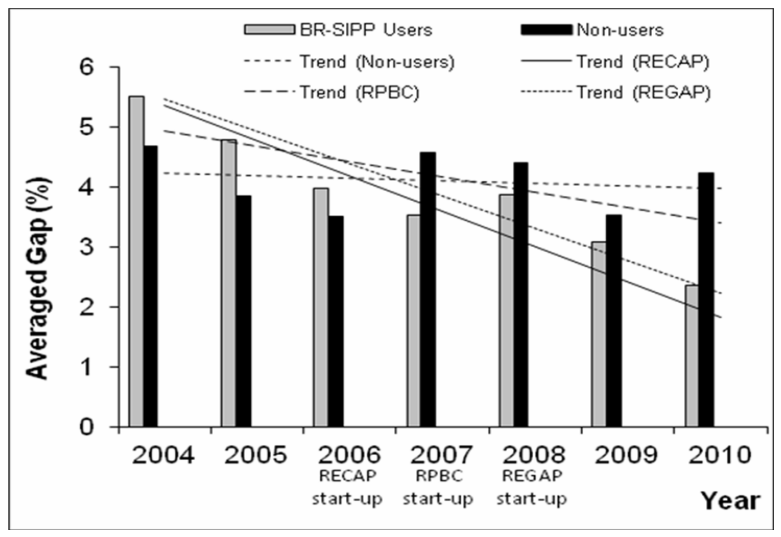

Figure 4: Relative gap between monthly planned and achieved production for users and non-users of BR-SIPP technology (average values per year).

Although it addresses a relatively simpler problem from a mathematical point of view, the development of corporate refinery planning technology was initiated later by Petrobras. In contrast to scheduling, commercial refinery planning technology could be considered to be mature in the 90's and commercial software indeed represented a very attractive alternative to provide immediate gains at that time. Around 1995, Petrobras started a plan to extensively introduce PIMS technology into its refining park. Despite the important benefits that have been obtained since then, advances in nonlinear algorithms allied to vertiginous IT evolution have encouraged Petrobras, as well as other energy companies (Guerra et al., 2010), to search for advanced refinery planning technology. 
At Petrobras, preliminary non-linear based planning applications were locally developed by refinery engineers for critical plant subsystems. Typically focusing on diesel production optimization, Petrobras REPLAN (diesel in-line blending operations) and RPBC (diesel process plant) refineries are illustrative examples where successful specialist planning tools have provided several million dollars per year in proven benefits (Moro et al., 1998). Similarly, a specialized nonlinear planning solution addressing the integrated problem of crude oil blending, the crude distillation unit (CDU) and the residue fluid catalytic cracking unit (RFCC) operation was also investigated at the RECAP refinery (Rodrigues and Joly, 2009) (Figure 5). Crude oil blending optimization models have also been developed by the REVAP refinery, along with approaches dedicated to short-term decisions on LPG (Pinto and Moro, 2000b) and fuel-oil and asphalt production (Joly et al., 2002).

The GAMS modeling system (Brooke et al., 1998) has been widely used to implement all these optimization models and their solution methods, which may readily be interfaced with a conventional spreadsheet, allowing its operation by non-GAMSoriented personnel (Figure 6). Although they are usually stand-alone applications, such developments have proven to be of capital importance for efficiently optimizing production planning and scheduling by accurately addressing quality issues, as well as plant operational rules and constraints, in a straightforward way.

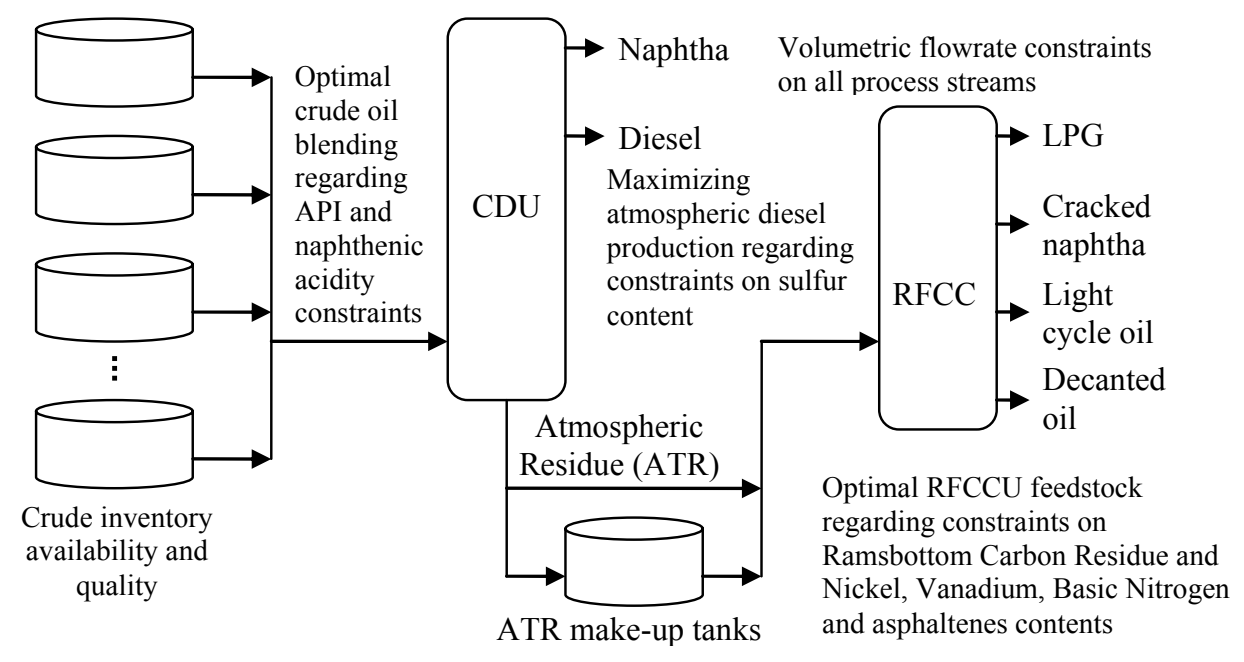

Figure 5: RECAP CDU-RFCC integrated non-linear planning model scope (Joly, 2009).

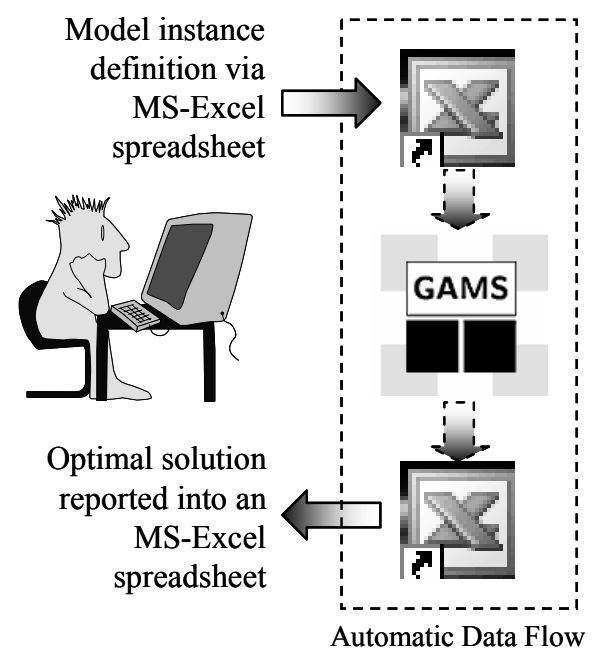

Figure 6: A GAMS-Excel integrated application. 
Underscored by these results, general-purpose developments arose about a decade later. An NLPbased application developed by Petrobras' OR-IT for supporting in-line blending planning optimization was the first representative result (Costa et al., 2008). In terms of plant-wide optimization solutions, the Petrobras Research \& Development Center (CENPES) has worked on the specification and development of an integrated refinery planning system able to perform technical-economic plant investment analyses. This development was started in 2006 and the first release has recently been successfully implemented at the RECAP refinery, as a pilot project (Aires et al., 2011). The use of commercial planning LP-based technology was then discontinued at RECAP and the proprietary solution is currently employed to define the refinery production targets on the basis of a rigorous non-linear solution approach embedded into an integrated web tool. Apart from allowing a more accurate representation of the refinery, several benefits have been obtained since then. Robust and reliable integration with other critical supply-chain systems, most of them also inhouse developed, have permitted identification and correction of systematic problems related to information availability and reliability. Being a multiuser system, the new tool has promoted not only ease of use by planners, but also a better level of interaction among remote process model experts in order to provide model maintenance and assistance under a userfriendly interface.

Continuous effort by CENPES and its technological partners is currently dedicated to aggregate new functionalities into the system, aiming at expanding its integration capabilities as well as automatic features, like process model adherence monitoring and updating. Algorithm technology prospection is currently being carried out according to distinct research directions, including mathematical programming and stochastic optimization, which has been demonstrated to suggest alternative solutions with smaller risk and with less loss in expected profit or upside potential (Pongsakdi et al., 2006; Chufu et al., 2008). In fact, failure to incorporate a stochastic description of the uncertain parameters in the production planning model can lead to a nonoptimal solution in reality.

Providing such technological autonomy is understood as strategic to positioning Petrobras at the state-of-the-art level of efficient refining decision-making technology, which clearly can be automatically replicated to sophisticate other inhouse large-scale decision-making applications currently employed to solve the global Petrobras supplychain.

\section{ROLE OF THE HUMAN FACTOR}

The production planning and scheduling teams of Petrobras refineries have a high profile in the organization. Whereas planners are quite often involved in a wide range of studies other than preparing the refinery monthly plan, such as medium/long-term economic analysis, plant performance monitoring and specialized model updating and upgrading together with other process engineers, schedulers play a major role in the day-to-day operations. Supporting the production scheduling activity from a head count viewpoint, European refineries have typically $4-10$ schedulers, depending mostly on the complexity of operations (Zhang and Valleur, 2010). In Brazilian refineries, however, the range is somewhat lower and the scheduling team is usually shared between refinery departments, namely the Optimization and Storage \& Transfer sectors. Some critical characteristics of a successful team have been identified:

- Motivated operational staff having a solid experience in the refinery and its logistical interface operation;

- "Bright engineers with open minds to find new solutions and test new tools", as emphasized by Zhang and Valleur (2010), and

- Polyvalent skills for prompt substitution and multidisciplinary assistance.

Changing attitudes, revising previous assumptions and rethinking best practices for refinery operation, are particular challenges for all involved in performing optimization. Rather than any computational systems, the quality of the staff is the prime success factor, along with their ability to work as a single team, despite focusing on distinct problems and tasks.

Regarding staff qualification, Petrobras ORoriented teams have structured a number of advanced long-term OR learning programs in order to popularize optimization concepts and large-scale optimization solution techniques based on professional algebraic modeling systems. Rather than technical knowledge, such programs delineate new cultures and opinions concerning how to operate the modern refining business. People set strategies, develop policies, standards and processes that will determine the global performance of the company. Best work processes enable the personnel to consistently achieve production plan objectives. Therefore, work process should be independent of personnel changes. Achieving this vision requires:

- Acquiring the business knowledge in advanced decision-making tools, which should allow increasing local and corporate visibility of plant operations; 
- Informing economic drivers about operations, allowing them to identify and eliminate constraints by better understanding the planning economic objectives;

- Analyzing actual production against the planned one, aiming at performing continuous modeling improvement;

- An efficient organization workflow where reliable information (data and models) is available on time.

Educating the refinery's personnel to work according to new paradigms and work processes is especially important because Petrobras is moving from several decades of a monopoly operating model to an open market environment. In this regard, in-line blending (ILB) can be presented as an illustrative example that has motivated not only nucleation of novel working philosophies, but also new challenging optimization developments in Petrobras throughout the last decade (Costa et al., 2008).

It is well established that blending is the last refinery's chance to impact profitability with a relatively low level of investments. In fact, of about 700 refineries worldwide, approximately 50\% have now modern inline blenders with on-line analyzers and blending software (Barsamian, 2007). In Petrobras, such a technology was implemented with pioneer ILB projects at REPLAN and REVAP refineries in the end of the 90's. Since then, thinking and working oriented towards "doing it right the first time" has driven local retraining people's attitudes and mindsets, aiming at supporting the "in-line blending unit": rapid communications, faster response times (analyzer repairs with high priority), key people on-call, and management incentives for ILB team members (Barsamian, 2007).

The ILB technology is currently being widely extended to other Petrobras refineries and long-term leading-edge studies related to in-line blending certification technology for petroleum products are being carried out by Petrobras together with academic partners. Potential benefits of such a technology may include (Barsamian, 2007, Valleur, 2007): reduced blendstock and finished product inventories waiting to be tested and reblended, increased availability of product to be blended and sold (spare in-line blender time available), optimized blend targets and product release giveaways, reduced ship demurrage, reduced time and manpower for blending, sampling tanks and laboratory tests (Figure 7), and lowering legal sample retention time.

Since blending technologies are a major concern as they impact the entire plant schedule and real-time optimization applications, a highly qualified and integrated refinery blending team becomes a key factor for success.

\section{A}
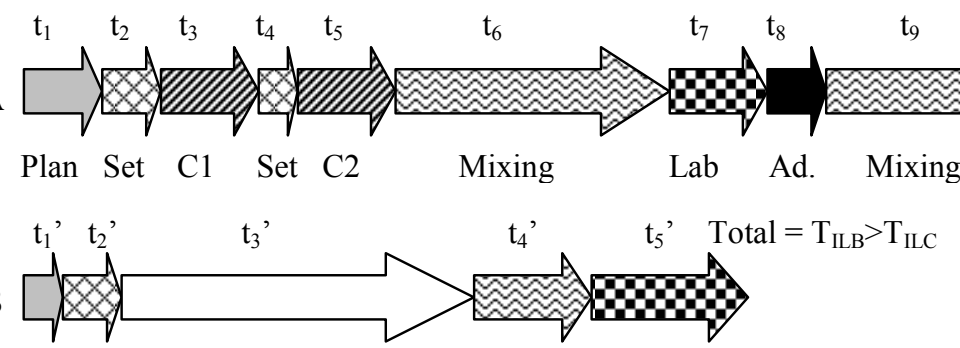

Plan Set In-line blending Circulate Lab Certif.

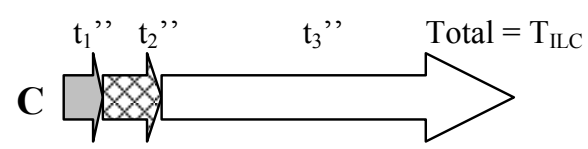

Plan Set In-line blending \& certif.

\begin{tabular}{lll|}
\hline Blend order planning & Tank mixing & Additives/corrections \\
Equipment set-up & 5 In-line blending & \\
Blend component pumping & Lab certification & \\
\hline
\end{tabular}

Figure 7: Time saving with in-line blending-based production technologies (adapted from Barsamian (2007)). A: Conventional time $\left(\mathrm{T}_{\mathrm{C}}\right)$ operation based on manual tank blending and certification; B: In-line blending time $\left(\mathrm{T}_{\mathrm{ILB}}\right)$ and conventional tank certification; $\mathrm{C}$ : In-line certification time $\left(\mathrm{T}_{\mathrm{ILC}}\right)$ of the finished blend product. 


\section{CONCLUSIONS}

An intelligent refinery production strategy is of paramount importance to ensure profitability, logistic reliability and customer satisfaction at the local and corporate levels. Refinery production planning/ scheduling activity must be understood as strategic in a number of ways.

Firstly, because it imposes the need for advanced tools that are based on multidisciplinary leading-edge expertise, part of which may be confidential, such as business knowledge, process models, blending correlations and product chemistry. Secondly, because it is supported by an experienced staff, whose expertise should encompass a valuable know-how on core refining business, chemical process engineering and $\mathrm{OR}$, which is required to interpret results and perform optimization in the technical sense of the word. Thirdly, because it integrates data, systems, technologies, work processes and people. Lastly, because it is a paradigm-breaking activity.

Clearly, the major issue is complexity: solving the optimal production problem of an oil refinery from incoming crude to end product dispatch is at the frontiers of the present stateof-the-art of OR technology. Once properly implemented, it may provide a step forward for the refining business. Therefore, an elevated degree of coordinated efforts from multidisciplinary areas of the organization is required. This should be pointed out as one of the major missions of the Petrobras refining sector today in order to successfully respond to present and future challenges in this field. Rather than optimization, refinery planning and scheduling means visibility from an operational point of view and, hence, safety.

\section{ACKNOWLEDGEMENTS}

The author is deeply thankful to Dr. Lincoln Fernando Lautenschläger Moro, Dr. Antonio Carlos Zanin (Petrobras/CETAI), Eng. Geraldo Márcio Diniz Santos (Petrobras Headquarters) and Eng. Celso Coelho Ferreira (Petrobras/RECAP) for their support and valuable comments.

\section{REFERENCES}

Aires, M. A. C., Ribas, P. C. and Joly, M., PLANREF - The Petrobras Refinery Planning Solution. In: Process Systems Engineering Workshop 2011, Angra dos Reis, Brazil (2011).
Agrawal, A. and Balasubramanian, K., Consider adopting next-generation refinery scheduling. Hydrocarbon Processing, September, 65-68 (2006).

Al-Shammari, A. and Ba-Shammakh, M. S., Uncertainty analysis for refinery production planning. Industrial \& Engineering Chemistry Research, 50, 7065-7072 (2011).

Albahri, T. E., Molecularly explicit characterization model (MECM) for light petroleum fractions. Industrial \& Engineering Chemistry Research, 44, 9286-9298 (2005).

Aye, M. M. S. and Zhang, N., A novel methodology in transforming bulk properties of refining streams into molecular information. Chemical Engineering Science, 60, 6702-6717 (2005).

Barsamian, A., Gasoline and Diesel Blending: Technology, Operations, Economics. Technical seminar (slides). Refinery Automation Institute, New Jersey (2007).

Bonner and Moore Management Science, RPMS (Refinery and Petrochemical Modeling System). A system description. Houston (1979).

Brooke, A., Kendrick, D., Meeraus, A. and Raman, R., GAMS - A user's guide, GAMS Development Corp., Washington (1998).

Charnes, A., Cooper, W. W. and Mellon, B., Blending aviation gasolines - A study in programming interdependent activities. Econometrica, 20 (1952).

Chufu, L., Xiaorong, H. E., Bingzhen, C., Qiang, X. and Chaowei, L., A hybrid programming model for optimal production planning under demand uncertainty in refinery. Chinese Journal of Chemical Engineering, 16, (2), 241-246 (2008).

Cooper, W. W., Abraham Charnes and W. W. Cooper (et al.): A brief history of a long collaboration in developing industrial uses of linear programming. Operations Research, 50, (1), 35-41 (2002).

Costa, F. L. P., Sousa, L. C. F., Joly, M., Takahashi, M. T., Magalhães, M. V. O. and Mendonça, P. N., Sistema de Otimização de Misturas. In: Rio Oil \& Gas 2008 Expo and Conference, Rio de Janeiro, Brazil (2008). (In Portuguese).

Garey, M. R. and Johnson, D. S., Computers and intractability - A Guide to the Theory of NPCompleteness. W.H. Freeman and Company, New York (1979).

Garvin, W. W., Crandall, H. W., John, J. B. and Spellman, R. A., Applications of linear programming in the oil industry. Management Science, 3, 407-430 (1957).

Guerra, O. J., Rodriguez, A. U., Montagut, S. M., Duarte, L. A. and Angarita, J. D., A solution 
strategy for large-scale nonlinear petroleum refinery planning models. In: AIChE Annual Meeting 2010, Minneapolis, USA (2010).

Guerra, O. J., Rodriguez, A. U., Montagut, S. M., Duarte, L. A. and Angarita, J. D., Advanced optimization in petroleum refinery planning. In: AIChE Annual Meeting 2011, Minneapolis, USA (2011).

Hu, S., Towler, G. and Zhu, X. X., Combine molecular modeling with optimization to stretch refinery operation. Industrial \& Engineering Chemistry Research, 41, 825-841 (2002).

$\mathrm{Hu}$, S. and Zhu, X. X., A general framework for incorporating molecular modeling into overall refinery optimization. Applied Thermal Engineering, 21, 1331-1348 (2001).

Joly, M., Moro, L. F. L. and Pinto, J. M., Planning and scheduling for petroleum refineries using mathematical programming. Brazilian Journal of Chemical Engineering, 19, (2), 207-228 (2002).

Joly, M. and Pinto, J. M., Mixed-integer programming techniques for the scheduling of fuel oil and asphalt production. Chemical Engineering Research and Design, 81, 427-447 (2003).

Joly, M. and Pinto, J. M., Role of Mathematical Modeling on the Optimal Control of HIV-1 Pathogenesis. AIChE Journal, 52, (3), 1-29 (2006).

Joly, M., Tecnologias de apoio à decisão para scheduling de refino - Parte II: Otimização. Revista Petro\&Química, 317, 46-50 (2009). (In Portuguese).

Kelly, J. D. and Mann, J. L., Crude oil blend scheduling optimization: an application with multimillion dollar benefits. Hydrocarbon Processing, 82, (6), 47-53 (2003).

Latur, P. R., APC for min maintenance or max profit? - Part 1. Hydrocarbon Processing, October, 15 (2009).

Lee, H., Pinto, J. M., Grossmann, I. E. and Park, S., Mixed-integer linear programming model for refinery short-term scheduling of crude oil unloading with inventory management. Industrial and Engineering Chemistry Research, 35, 16301996 (1996).

Magalhães, M. V. O., Refinery scheduling. Ph.D. Thesis, Imperial College (2004).

Magalhães, M. V. O., Moro, L. F. L., Smania, P., Hassimoto, M. K., Pinto, J. M. and Abadia, G. J., SIPP - A Solution for Refinery Scheduling. In: NPRA Computer Conference, San Antonio, USA (1998).

Magatão, L., Arruda, L. V. R. and Neves-Jr, F., A combined CLP-MILP approach for scheduling commodities in a pipeline. Journal of Scheduling, 14, 57-87 (2011).

Maravelias, C. T. and Sung, C., Integration of production planning and scheduling: overview, challenges and opportunities. Computers \& Chemical Engineering, 33, 1919-1930 (2009).

Moro, L. F. L., Zanin, A. C. Z. and Pinto, J. M., A planning model for refinery diesel production. Computers \& Chemical Engineering, 22, S-1039S1042 (1998).

Moro, L. F. L., Process technology in the petroleum refining industry - Current situation and future trends. Computers \& Chemical Engineering, 27, 1303-1305 (2003).

Moro, L. F. L., Optimization in the petroleum refining industry - the virtual refinery. In: $10^{\text {th }}$ International Symposium on Process Systems Engineering. Alves, R. M. B., Nascimento, C. A. O, Biscaia Jr., E. C. (Editors), Salvador, Brazil (2009).

Neiro, M. S. N. and Pinto, J. M., A general modeling framework for the operational planning of petroleum supply chains. Computers \& Chemical Engineering, 28, 871-896 (2004).

Pinto, J. M. and Moro, L. F. L., A planning model for petroleum refineries. Brazilian Journal of Chemical Engineering. 17, (4-7), 575-586 (2000a).

Pinto, J. M. and Moro, L. F. L., A mixed-integer model for LPG scheduling. In: ESCAPE $10-$ European Symposium on Computer-Aided Process Engineering. Florence, Italy (2000b).

Pongsakdi, A., Rangsunvigit, P., Siemanond, K. and Bagajewicz, M. J., Financial risk management in the planning of refinery operations. International Journal of Production Economics, 103, 64-86 (2006).

Rodrigues, M. S. and Joly, M., Tecnologias de apoio à decisão para scheduling de refino - Parte I: Simulação. Revista Petro\&Química, 316, 44-48 (2009). (In Portuguese).

Symonds, G. H., Linear programming: the solution of refinery problems. Technical Report, Esso Standard Oil Co (1955).

Swensen, M. and Acuff, C., Rethink planning and scheduling's role in refinery optimization. Hydrocarbon Processing, Special Report - June, 55-58 (2011).

Valleur, M., In-line certification of petroleum products. Technical seminar (slides), Technip, Paris (2007).

Vavasis, S., Nonlinear optimization: complexity issues. Oxford University Press, New York (1991). 
Zhang, N., Optimisation is key to high-performing refineries. Business Briefing: Oil \& Gas Processing Review, 33-35 (2006).

Zhang, N. and $\mathrm{Wu}, \mathrm{Y}$., Molecular management of gasoline streams. Chemical Engineering Transactions, 18, 749-754 (2009).

Zhang, N. and Valleur, M., Refinery planning and scheduling. Handbook of Petroleum Refining and Natural Gas Processing, Chapter 18. ASTM International, Conshohocken (2010).

$\mathrm{Wu}, \mathrm{Y}$. and Zhang, N., Molecular characterization of gasoline and diesel streams. Industrial and Engineering Chemistry Research, 49, 1277312782 (2010). 